\title{
Association of obesity with socioeconomic status among adults of ages 18 to 80 years in rural Northwest China
}

\author{
Leilei Pei ${ }^{1}$, Yue Cheng ${ }^{2}$, Yijun Kang ${ }^{1}$, Shuyi Yuan ${ }^{1}$ and Hong Yan ${ }^{1 *}$
}

\begin{abstract}
Background: Understanding social disparities in obesity are presently an essential element in establishing public health priorities. However, the association between socioeconomic status (SES) and obesity has not been assessed in rural Northwest China. This study aims to explore the effect of SES on overweight/obesity and abdominal obesity by gender and age in rural Northwest China.
\end{abstract}

Methods: A total of 3030 participants between the ages of 18 to 80 years from rural Hanzhong, Shaanxi province, Northwest China were enrolled in our study using a two-level stratified random cluster sampling technique.

Adjusted odds ratio (AOR) were used to assess the relationship between socioeconomic status and obesity after controlling for confounding factors using logistic regression.

Results: Our results indicated that the prevalence of abdominal obesity (38.8\%) was the highest in rural Northwest China when compared with overweight (27.8\%) and obesity (5.7\%). When adjusting for possible risk factors, there were significant gender disparities in SES-obesity association. In men, the likelihoods of overweight/obesity and abdominal obesity were higher in the high SES groups when compared to the low SES groups. However, women with a high level of education were less likely to have overweight/obesity (AOR:0.78, 95\% Cl: 0.62, 0.98) than their counterparts with a low level of education. After the inclusion of multiple lifestyle factors, we still observed a strong positive association between age and obesity in the population.

Conclusions: Both gender and age differences in SES-obesity association were clearly observed in our study. Therefore, interventional measures should be employed in rural Northwest China to reduce the obesity epidemic that specifically takes into account gender and age differences.

Keywords: Obesity, Socioeconomic status, Lifestyles, Disparity

\section{Background}

Obesity has recently become a major public health problem worldwide and is attributed to high-energy intake or low physical activity levels [1]. In particular, abdominal obesity which is characterized by excessive abdominal fat around the stomach and abdomen, is strongly associated with increased risk of heart disease, hypertension, insulin resistance, type 2 diabetes, asthma, Alzheimer's Disease as well as various other diseases [2-4]. Globally, approximately 1.5 billion adults were overweight (defined

\footnotetext{
*Correspondence: yhpaper605@sina.com

'Department of Epidemiology and Health Statistics, School of Public Health, Xi'an Jiaotong University Health Science Center, No. 76 West Yanta Road, PO Box 46, Xi'an, Shaanxi 710061, PR China

Full list of author information is available at the end of the article
}

by $\mathrm{BMI} \geq 25 \mathrm{~kg} / \mathrm{m}^{2}$ ) in 2008 , and more than one third of them were obese [5]. Understanding social disparities in health status is presently an important topic on the government health agenda and an essential element in establishing public health priorities. A strong association between socioeconomic status (SES) and obesity has also been widely confirmed [6]. People of low-SES are at greater risk of becoming overweight and obese than people with high SES across all industrial countries, whereas in developing countries people of high-SES people are at increased risk of becoming overweight $[7,8]$. China is the most populous country in the world, whose total population accounts for one-fifth of the global population. With a large economic development over the past decades, many dramatic 
changes in lifestyles have occurred among the residents of China. Recent studies suggest that between 1992 and 2002, more than 60 million people in China became obese [9]. However, there is an extreme imbalance in the economic development burdened by different regions of China with lower SES levels found in Northwest areas. Thus, a profound understanding of the SES-obesity relationship in Northwest China can provide meaningful insights for developing effective obesity-prevention and -management programs and policies.

In 2010, we conducted a large investigation on the impact of obesity in rural residents of ages 18 to 80 years in Hanzhong, Shaanxi province in Northwest China. In the present study, our primary objective is to analyze the association between SES and obesity by gender and age among residents in the surveyed areas. To our knowledge, this is the first study to systemically examine the influence of SES on obesity and lifestyles among adults in rural Northwest China.

\section{Methods}

\section{Study design and participants}

A cross-sectional population-based epidemiological and risk factor survey was conducted in 2010 in rural areas of Hanzhong, Shaanxi provinces, in Northwest China. The target population of the survey was adult residents between the ages of 18 to 80 years, who were recruited using a two-level stratified random cluster sampling technique. There were nine townships in the study area and about 17 (15 to 36) villages in each township. Each township was a stratum and one village was randomly chosen from each township. According to local demographic data, all available and eligible adults in the chosen villages were informed and invited to participate in the survey. Hence, it was expected that approximately 3600 participants could be recruited for the survey.

Data for the participants included socio-demographic characteristics and lifestyles, which were obtained by face-to-face interviews with a structured questionnaire. Anthropometric measurements were performed by standard methods using calibrated instruments in an empty room in every village. Standing height was measured using a non-stretchable tape (214 Road $\operatorname{Rod}^{\text {Tw }}$, USA), with the maximum distance from the floor to the highest point on the head facing directly ahead. Participant's feet were put together without shoes and the arms were placed on either side when the measurements were made. In addition, heels, buttocks and upper back were also in contact with the wall (accurate to $1 \mathrm{~mm}$ ). Weight was measured using a calibrated electronic scale (Tanita HD-305, Japan) with an accuracy of 0.1 kilograms. Waist circumference (WC; $\mathrm{cm}$ ) was measured as the minimum circumference between the inferior margin of the ribcage and the crest of the ileum.
Trained field staff from Xi'an Jiaotong University Health Science Center conducted the questionnaire surveys and anthropometric measures. The investigation team consisted of ten to twelve members and one supervisor. During the survey, all field workers were closely monitored by their supervisors and randomly examined. Participants were also re-interviewed when errors and/ or missing values were detected. Informed consent was obtained from each participant at the start of the survey. This study was reviewed and approved by the Human Research Ethics Committee of the Xi'an Jiaotong University Health Science Center.

\section{Research indicators}

Body mass index (BMI; $\mathrm{kg} / \mathrm{m}^{2}$ ) and waist circumference were used for the assessment of overweight/obesity and abdominal obesity, respectively. In view of the lower obesity-associated metabolism in Chinese people compared to European/North American populations, the Chinese BMI and WC cut-off points proposed by the Working Group on Obesity in China (WGOC) were used to define overweight/obesity and abdominal obesity [10-12]. In this study, overweight and obesity were defined as follows: $24.0 \mathrm{~kg} / \mathrm{m}^{2} \leq \mathrm{BMI} \leq 27.9 \mathrm{~kg} / \mathrm{m}^{2}$ (overweight), and $\mathrm{BMI} \geq 28.0 \mathrm{~kg} / \mathrm{m}^{2}$ (obesity) [13]. Abdominal obesity was gender-specific and defined as: $W C \geq 80 \mathrm{~cm}$ for women, and $\mathrm{WC} \geq 85 \mathrm{~cm}$ for men [14]. In order to extend comparisons, different BMI $(\geq 23, \geq 24, \geq 25, \geq 28, \geq 30 \mathrm{~cm})$ and WC ( $\geq 80, \geq 85, \geq 88, \geq 90, \geq 94, \geq 102 \mathrm{~cm})$ cut-offs for defining overweight/obesity and abdominal obesity were also adopted.

SES of respondents in surveyed areas was measured by combining the participants mean annual net income per capita and education level, which was then categorized as tertiles indicating the poor, middle and wealthiest income households. The low-SES group was used as a reference and two dummy variables were used to code middle and high SES. Similarly, the age of participants was also classified into tertiles ( $\leq 44$ years, $45 \sim 54$ years and $\geq 55$ years ). According to previous studies [15,16], variables related to the participants' lifestyles were categorized into two levels, e.g. farming frequency $(<3$ times/week and $\geq 3$ times/week), hours of TV viewing $(<2 \mathrm{~h} /$ day and $\geq 2 \mathrm{~h} /$ day), smoking frequency (no smoking and $\geq 1$ cigarette/day), drinking alcohol frequency (no and $\geq 1 /$ week) as well as amount of vegetable and fruit consumption (<500 g/week and $\geq 500 \mathrm{~g} /$ week).

\section{Statistical analysis}

Data was expressed as numbers or percentages and presented as mean with standard error of the mean. Intersubgroup differences were examined by Chi-square test and two-tailed t-test. The standardized age prevalence of overweight/obesity and abdominal obesity was calculated 
by a direct method using 2010 China population census data as the standard population. For assessing the effects of annual net income per capita and education level on overweight/obesity and abdominal obesity for participants by gender and age, an adjusted odds ratio (AOR) was obtained by a multivariate logistic regression analysis after controlling for socio-demographic characteristics and risk factors. The SPSS 13.0 (SPSS Inc., Chicago, Illinois, USA) was used for all statistical analysis and significance was achieved from statistical tests when $P<0.05$.

\section{Results}

\section{Participant's baseline characteristics}

A total of 3030 eligible participants between the ages of 18 to 80 years were included from surveyed areas, with a response rate of $84.17 \%$ (Table 1). The mean age amongst participants was $50.04 \pm 11.80$ years, with women accounting for $65.3 \%$ of the total number of participants. The average number of years of education for the participants was $6.77 \pm 3.72$ years (range $0-18$ years). Among the participants, $28.4 \%$ were from poor households, $32.4 \%$ were from middle households, while $39.2 \%$ were from wealthy households based on the annual net income per capita. The mean BMI and WC were significantly higher in men than women $(P<0.05)$. Gender differences were also observed in the rural Hanzhong participants' in terms of age, education years as well as employment, income and marriage status $(P<0.001)$. With respect to the participants' lifestyle, our study revealed that women had a significantly higher frequency for farming, but lower alcohol consumption, hours of TV viewing and smoking frequency than men.

Prevalence of overweight/obesity and abdominal obesity in rural Northwest China

Based on BMI and WC cut-offs standards associated with the Chinese population, the prevalence of overweight, obesity and abdominal obesity was $27.8 \%, 5.7 \%$ and $38.8 \%$, respectively, in rural Hanzhong, Shaanxi province. The age-standardized percentage of overweight and obesity was $23.4 \%$ and $5.9 \%$, respectively $(24.7 \%$ (overweight) and $7.5 \%$ (obesity) in men and $22.8 \%$ (overweight) and $4.5 \%$ (obesity) in women). The agestandardized percentage of abdominal obesity was $32.5 \%$ (31.1\% in men and $31.5 \%$ in women).

Our results revealed that there is a discrepancy in the prevalence of overweight, obesity and abdominal obesity across different socio-demographic groups and lifestyles as shown in Table 2. Among female participants, the prevalence of obesity increased with age. There was also a significant difference in the prevalence of obesity across education levels and lifestyles, such as farming frequency as well as vegetable and fruit consumption. In men, a higher prevalence of overweight and abdominal
Table 1 Socio-demographic characteristics and lifestyles of enrolled adult participants at the age of 18 to 80 years in rural Hanzhong, Shaanxi province in $2010^{\mathrm{a}}$

\begin{tabular}{llll}
\hline Socio-demographic variables $^{\mathbf{b}}$ & Female & Male & Total \\
\hline${\text { Body mass index }\left(\mathrm{BMl} ; \mathrm{kg} / \mathrm{m}^{2}\right)^{*}}$ & $22.91(3.22)$ & $22.95(5.52)$ & $22.92(4.17)$ \\
Waist circumference $(\mathrm{WC} ; \mathrm{cm})^{*}$ & $78.08(8.64)$ & $81.37(9.12)$ & $79.22(8.95)$ \\
Age (years)* & & & \\
$\quad \leq 44$ & $664(33.8)$ & $317(30.3)$ & $981(32.6)$ \\
$\quad 45 \sim 54$ & $674(34.3)$ & $315(30.1)$ & $989(32.9)$ \\
$\quad \geq 55$ & $626(31.9)$ & $414(39.6)$ & $1040(34.6)$ \\
Marriage status* & & & \\
$\quad$ Married & $1803(98.7)$ & $955(95.7)$ & $2758(97.6)$ \\
$\quad$ Single/divorced/widowed & $24(1.3)$ & $43(4.3)$ & $67(2.4)$ \\
Employment status* & & & \\
$\quad$ Farming & $1787(90.7)$ & $807(77.3)$ & $420(13.9)$ \\
$\quad$ No farming & $183(9.3)$ & $237(22.7)$ & $2594(86.1)$
\end{tabular}

Level of education*

$\begin{array}{llll}\text { Low } & 627(32.0) & 177(16.9) & 804(26.7) \\ \text { Middle } & 426(21.7) & 228(21.8) & 654(21.7) \\ \text { High } & 908(46.3) & 642(61.3) & 1550(51.5)\end{array}$

Annual net income per capita*

$\begin{array}{llll}\text { Low } & 517(26.9) & 323(31.2) & 840(28.4) \\ \text { middle } & 659(34.3) & 299(28.9) & 958(32.4) \\ \text { High } & 745(38.8) & 412(39.8) & 1157(39.2)\end{array}$

Lifestyles $^{c}$

Farming frequency*

$\begin{array}{llll}<3 \text { times/week } & 677(34.7) & 408(39.5) & 1085(35.8) \\ \geq 3 \text { times/week } & 1274(65.3) & 624(60.5) & 1898(63.6)\end{array}$

Hours of TV viewing*

$\begin{array}{llll}<2 \text { h/day } & 756(40.1) & 311(30.3) & 1067(36.7) \\ \geq 2 \text { h/day } & 1128(59.9) & 716(69.6) & 1844(63.3)\end{array}$

Alcohol consumption*
0 times/week
$1902(97.8) \quad 842(81.7)$
$2744(92.2)$
$\geq 1$ times/week
$43(2.2)$
$188(18.3)$
$231(7.8)$

Smoking frequency*

$$
\begin{array}{llll}
0 \text { cigarette/day } & 1925(99.2) & 379(36.4) & 2304(77.2) \\
\geq 1 \text { cigarette/day } & 16(0.8) & 663(63.6) & 679(22.8)
\end{array}
$$

Vegetable and fruit consumption

$\begin{array}{llll}<500 \mathrm{~g} / \text { week } & 1411(73.0) & 761(74.2) & 2172(73.5) \\ \geq 500 \mathrm{~g} / \text { week } & 521(27.0) & 264(25.8) & 785(26.5) \\ & 1978 & 1052 & 3030\end{array}$

${ }^{a}$ Values are given as mean (SD) or the number (percentage) of the study population across socio-demographic characteristics by gender.

${ }^{\mathrm{b}}$ Missing values for socio-demographic characteristics: 16 for Employment status, 75 for income, 22 for education, 205 for marriage, 20 for age.

'Missing values for lifestyles: 73 for Vegetable and fruit consumption, 47 for Farming frequency and Smoking frequency, 55 for Alcohol consumption, 119 for Hours of TV viewing.

*Denotes $\mathrm{P}<0.05$ for differences in socio-demographic characteristics and lifestyles by gender. 
Table 2 Prevalence of overweight, obesity and abdominal obesity among the study population across different socio-demographic characteristics and lifestyles by gender in rural Hanzhong, Shaanxi province in $2010^{\mathrm{a}}$

\begin{tabular}{|c|c|c|c|c|c|c|c|c|c|}
\hline \multirow[b]{3}{*}{ Socio-demographic characteristics } & \multicolumn{3}{|c|}{ Overweight } & \multirow{2}{*}{\multicolumn{3}{|c|}{$\begin{array}{l}\text { Obesity } \\
\left(\mathrm{BMI} \geq 28 \mathrm{~kg} / \mathrm{m}^{2}\right)\end{array}$}} & \multirow{2}{*}{\multicolumn{3}{|c|}{$\begin{array}{l}\text { Abdominal obesity } \\
\text { (WC } \geq 80 \mathrm{~cm} \text { for female } \\
\text { and } \geq 85 \mathrm{~cm} \text { for male) }\end{array}$}} \\
\hline & \multicolumn{3}{|c|}{$\left(24.0 \mathrm{~kg} / \mathrm{m}^{2} \leq \mathrm{BMI} \leq 27.9 \mathrm{~kg} / \mathrm{m}^{2}\right)$} & & & & & & \\
\hline & Female & Male & Total & Female & Male & Total & Female & Male & Total \\
\hline \multicolumn{10}{|l|}{ Age } \\
\hline$\leq 44$ & $173(26.1) \dagger$ & $115(36.3)$ & $288\left(29.4^{) \neq}\right.$ & $24(3.6)^{\dagger}$ & $22(6.9)$ & $46(4.7)^{)^{\ddagger}}$ & $207(31.2)^{\dagger}$ & 104(32.8) & $311(31.7)^{1 \neq}$ \\
\hline $45 \sim 54$ & 249(36.9) & 114(36.2) & $363(36.7)$ & $36(5.3)$ & $18(5.7)$ & $54(5.5)$ & 295(43.8) & 123(39.0) & $418(42.3)$ \\
\hline$\geq 55$ & 223(35.6) & 126(30.4) & 349(33.6) & $50(8.0)$ & 23(5.6) & $73(7.0)$ & $300(48.1)$ & 139(33.6) & $439(42.3)$ \\
\hline \multicolumn{10}{|l|}{ Marriage status } \\
\hline Married & 593(32.9) & $337(35.3)^{*}$ & $930(33.7)^{\ddagger \neq}$ & $100(5.5)$ & $60(6.3)$ & $160(5.8)$ & $731(40.5)$ & $342(35.8)^{*}$ & $1073(38.9)^{1 \neq}$ \\
\hline Single/divorced/widowed & $5(20.8)$ & $5(11.6)$ & 10(14.9) & $1(4.2)$ & $2(4.7)$ & $3(4.5)$ & $7(29.2)$ & $5(11.6)$ & 12(17.9) \\
\hline \multicolumn{10}{|l|}{ Employment status } \\
\hline Farming & $592(33.1)$ & $259(32.1)^{*}$ & $851(32.8)$ & 100(5.6) & $42(5.2)^{*}$ & $142(5.5)$ & $741(41.5)$ & $263(32.6)^{*}$ & 1004(38.7) \\
\hline No farming & $57(31.1)$ & 97(40.9) & 154(36.7) & $10(5.5)$ & $21(8.9)$ & $31(7.4)$ & $64(35.0)$ & $102(43.0)$ & $166(39.5)$ \\
\hline \multicolumn{10}{|l|}{ Level of education } \\
\hline Low & $220(35.1)$ & $39(22.0)^{*}$ & 259(32.2) & $42(6.7)$ & $7(4.0)$ & $49(6.1)$ & $287(45.8) \dagger$ & $52(29.4)^{*}$ & $339(42.2)$ \\
\hline Middle & $147(34.5)$ & 75(32.9) & $222(33.9))$ & $29(6.8)$ & $17(7.5)$ & $46(7.0)$ & $181(42.5)$ & $70(30.7)$ & 251(38.4) \\
\hline High & 279(30.7) & $242(37.7)$ & $521(33.6)$ & $39(4.3)$ & $39(6.1)$ & $78(5.0))$ & $335(37.0)$ & 244(38.0) & $579(37.4)$ \\
\hline \multicolumn{10}{|l|}{ Annual net income per capita } \\
\hline Low & 152(29.4) & $84(26.0)^{*}$ & $236(28.1)^{) \ddagger}$ & 30(5.8) & $15(4.6)$ & $45(5.4)$ & $210(40.7)$ & $94(29.1)^{*}$ & 259(32.2) \\
\hline Middle & $221(33.5)$ & 113(37.8) & 334(34.9) & $39(5.9)$ & $24(8.0)$ & $63(6.6)$ & $271(41.2)$ & $120(40.1)$ & 222(33.9) \\
\hline High & $261(35.0)$ & 156(37.9) & $417(36.0)$ & $36(4.8)$ & $24(5.8)$ & $60(5.2)$ & $304(40.8)$ & 150(36.4) & $521(33.6)$ \\
\hline \multicolumn{10}{|l|}{ Lifestyles } \\
\hline \multicolumn{10}{|l|}{ Farming frequency } \\
\hline$<3$ times/week & $236(34.9)$ & $168(41.2)^{*}$ & $404(37.2)^{1 \neq}$ & $51(7.5)^{\dagger}$ & $34(8.3)^{*}$ & $85(7.8)^{) \ddagger}$ & $291(43.0)$ & $163(40.0)^{*}$ & $454(41.9)^{1 \ddagger}$ \\
\hline$\geq 3$ times/week & 407(31.9) & 182(29.2) & 589(31.0) & $59(4.6)$ & $28(4.5)$ & $87(4.6)$ & $508(39.9)$ & 197(31.6) & 705(37.2) \\
\hline \multicolumn{10}{|l|}{ Hours of TV viewing } \\
\hline$<2$ h/day & 237(31.3) & 93(29.9) & $330(30.9)^{) \neq}$ & $45(6.0)$ & $19(6.1)$ & $64(6.0)$ & $313(41.5)$ & 102(32.8) & $415(38.9)$ \\
\hline$\geq 2$ h/day & $380(33.7)$ & $258(36.0)$ & 638(34.6) & $58(5.1)$ & $43(6.0)$ & $101(5.5)$ & $456(40.5)$ & $259(36.2)$ & 715(38.8) \\
\hline \multicolumn{10}{|l|}{ Alcohol consumption } \\
\hline 0 times/week & 630(33.1) & 285(33.8) & 915(33.3) & $110(5.8)$ & $53(6.3)$ & 163(5.9) & $779(41.0)$ & $292(34.7)$ & $1071(39.0)$ \\
\hline$\geq 1$ times/week & $11(25.6)$ & 67(35.6) & 78(33.8) & $0(0.0)$ & $9(4.8)$ & $9(3.9)$ & $17(39.5)$ & $70(37.2)$ & $87(37.7)$ \\
\hline \multicolumn{10}{|l|}{ Smoking frequency } \\
\hline 0 cigarette/day & 635(33.0) & $153(40.4)^{*}$ & 788(34.2) & 107(5.6) & $25(6.6)$ & $132(5.7)$ & $787(40.9)$ & $151(39.8)^{*}$ & $938(40.7)^{1 \neq}$ \\
\hline$\geq 1$ cigarette/day & $5(31.3)$ & $202(30.5)$ & 207(30.5) & $2(12.5)$ & $38(5.7)$ & $40(5.9)$ & $7(43.8)$ & 215(32.4) & $222(32.7)$ \\
\hline \multicolumn{10}{|l|}{ Vegetable and fruit consumption } \\
\hline$<500 \mathrm{~g} /$ week & $446(31.6)^{*}$ & $252(33.1)$ & $698(32.1)^{\ddagger \neq}$ & 83(5.9) & $43(5.7)$ & $126(5.8)$ & $561(39.8)^{*}$ & $254(33.4)^{*}$ & $815(37.5)^{1 \ddagger}$ \\
\hline$\geq 500 \mathrm{~g} /$ week & 188(36.1) & $99(37.5)$ & 287(36.6) & $26(5.0)$ & $19(7.2)$ & $45(5.7)$ & 229(44.0) & 107(40.5) & $336(42.8)$ \\
\hline Total & $650(32.9)$ & 356(33.8) & 1003(33.2) & $63(6.0)$ & $110(5.6)$ & 173(5.7) & $366(34.8)^{*}$ & $808(40.9)$ & 1174(38.8) \\
\hline
\end{tabular}

Values represent the number of overweight, obesity and abdominal obesity and the prevalence is included in the bracket.

*Denote $\mathrm{P}<0.05$, suggesting a significant difference in overweight, obesity and abdominal obesity by socio-demographic characteristics and lifestyles among male adults. ${ }^{\dagger}$ Denote $\mathrm{P}<0.05$ for prevalence of overweight, obesity and abdominal obesity across socio-demographic characteristics and lifestyles among female adults.

${ }^{\ddagger}$ Denote $\mathrm{P}<0.05$ for comparison across different socio-demographic characteristics and lifestyles in total population.

obesity was observed with a higher income and level of education. Marriage and employment status was also related to obesity in men. Amongst men with low farming activity frequency and smoking frequency as well as high vegetable and fruit intake, there was a high prevalence of obesity. 
BMI percentage cutoffs of $\geq 23, \geq 24, \geq 25, \geq 28, \geq 30 \mathrm{~kg} /$ $\mathrm{m}^{2}$ among the participants in rural Hanzhong were as follows: $45.5 \%, 33.2 \%, 22.7 \%, 5.7 \%$ and $1.7 \%$ respectively. By gender, the BMI percentages cutoffs of $\geq 23, \geq 24, \geq 25, \geq 28$ and $\geq 30 \mathrm{~kg} / \mathrm{m}^{2}$ in study areas were $46.0 \%, 32.9 \%, 21.6 \%$, $5.6 \%$ and $1.5 \%$, respectively, for women and $44.5 \%, 33.8 \%$, $24.7 \%, 6.0 \%$ and $2.0 \%$, respectively, for men. WC percentage cutoffs of $\geq 80, \geq 85, \geq 88, \geq 90, \geq 94$ and $\geq 102 \mathrm{~cm}$ were $40.9 \%, 22.1 \%, 13.7 \%, 9.6 \%, 4.7 \%$ and $0.8 \%$, respectively for women and $54.3 \%, 34.8 \%, 23.8 \%, 19.4 \%, 11.2 \%$ and $2.1 \%$, respectively for men.

\section{The association of obesity with SES in rural Northwest China}

As shown in Table 3, there is a statistically significant correlation between obesity and SES associated with gender amongst the participants in rural Hanzhong, when adjusting for socio-demographic and risk factors analyzed in the study and using a logistic regression model. It could be found that the association between SES and obesity was statistically significant only when BMI was used for the female population, meanwhile a significant association was observed in males for both parameters (BMI and WC). For example, women with a high level of education were less likely to have overweight/obesity (AOR:0.78, 95\% CI: $0.62,0.98)$ than their counterparts with a low level of education. However, amongst men, it was noted that a higher risk of overweight/obesity was found in higher education (AOR:2.26, 95\% CI: 1.50, 3.42) or income group (AOR: 1.74,95\% CI: 1.25,2.42) when compared to the low education or income group. Men with a high level of education (AOR:1.64, 95\% CI: 1.12, 2.41) or income (AOR:1.52, $95 \%$ CI: $1.10,2.11$ ) were also more likely to have abdominal obesity than their counterparts with a low level of education or income. The results above suggested that there was a clear gender difference in the association between SES and overweight/obesity. Furthermore, being a woman, the person had a lower risk of being overweight/obese (AOR: 0.77, 95\% CI: 0.60, 0.98) compared to a man.

An analysis of SES-obesity association stratified by age groups was also performed after adjusting for sociodemographic and risk factors analyzed in the study (Table 3). Among the youngest participants, we found that participants of medium (AOR:2.14, 95\% CI: 1.16, 3.94) and high (AOR:1.80, 95\% CI: 1.01, 3.19) education level had a higher likelihood of overweight/obesity than those in the low-education group. Among the elderly participants, we also observed that participants with a medium income were more likely to be abdominally obese (AOR:1.76, 95\% CI: $1.29,2.42$ ) and overweight/obese (AOR:1.67, 95\% CI: 1.20, $2.30)$ in contrast with those with a low-income. After controlling for socio-demographic and risk factors, a strongly positive association was still observed between age and obesity in the participants.

\section{The relationship between lifestyle and SES}

When adjusting for socio-demographic factors, an association between lifestyle and SES was also observed by gender, when using low-SES as the reference group (Table 4). Our study showed that the SES disparities in lifestyles including farming frequency, TV viewing as well as vegetable and fruit consumption was pronounced for women. Among female participants in surveyed areas, the duration of TV viewing as well as amount of vegetable and fruit consumption were found to increase with income and education level, whereas farming frequency was just the opposite. Among men, farming frequency also decreased with the increment of income and education level, while duration of TV viewing as well as amount of vegetable and fruit consumption increased with income and education level. Women reported lower duration of TV viewing, alcohol consumption and smoking frequency than men, but displayed increased farming frequency. Furthermore, SES disparities in lifestyles across the youngest and oldest groups were also observed and shown in the Table 4 . In the youngest participants, a positive association was clearly observed between amount of vegetable and fruit consumption and increased income. In addition, duration of TV viewing was much more in participants of medium and high education than that of low education. There was also an inverse correlation between farming frequency and SES. Among the oldest participants, on the whole, consumption of vegetable and fruit, alcohol intake, smoking frequency and duration of TV viewing were positively associated with SES. Furthermore, it was evident that the oldest participants had less duration of TV viewing, alcohol consumption as well as consumption of vegetable and fruit, as well as did more farm work.

\section{Discussion}

In this study, we examined the prevalence of overweight/ obesity and abdominal obesity as well as their associations with SES in rural Hanzhong, Northwest China in 2010. Our results indicated that the prevalence of abdominal obesity was higher in rural Northwest China when compared with overweight or obesity. Overall, it also appears that there is a significant difference in the SES-obesity association by gender in rural Northwest China. Additionally, the relationship between SES and the participants' lifestyle may be an important influencing factor that warrants further exploration.

Results indicated that the crude prevalence of overweight and obesity was $33.2 \%$ (age-standardized percentage $28.9 \%$ ) and $5.7 \%$ (age-standardized percentage 5.3\%), respectively, among participants in rural Hanzhong, Northwest China in 2010. The figures reported from other studies conducted in China have varied considerably. For instance, approximately $37.5 \%$ of adults in Zhejiang province in 2009 were reported 
Table 3 The association between obesity and SES among enrolled adult participants aged 18-80 years by gender and age groups in rural Hanzhong, Shaanxi province in $2010^{\text {ab }}$

\begin{tabular}{lll} 
Class differences & Abdominal obesity & $\begin{array}{l}\text { Overweight/ } \\
\text { obesity }\end{array}$ \\
& (WC $\geq 85 \mathrm{~cm}$ for male and \\
& WC $\geq 80 \mathrm{~cm}$ for female) & $\left(\mathrm{BMI} \geq 24 \mathrm{~kg} / \mathrm{m}^{2}\right)$ \\
\hline
\end{tabular}

Female

Annual net income

per capita

$\begin{array}{ll}\text { Medium } & 1.23(0.97,1.57) \\ \text { High } & 1.22(0.96,1.56)\end{array}$

$1.38(1.06,1.78)^{*}$

$1.49(1.16,1.92)^{*}$

Level of education

$\begin{array}{ll}\text { Medium } & 0.89(0.69,1.14) \\ \text { High } & 0.69(0.56,0.86)^{*}\end{array}$

Male

Annual net income per capita

\section{Medium}

High

Level of education

Medium

High

Gender differences

$\begin{array}{ll}\text { Men } & 1.00 \\ \text { Women } & 1.08(0.91,1.28)\end{array}$

The youngest

participants

Annual net income per capita

Medium
High

Level of education

Medium $\quad 1.36(0.79,2.35)$

The oldest participants

Annual net income per capita

$\begin{array}{ll}\text { Medium } & 1.76(1.29,2.42)^{*} \\ \text { High } & 1.18(0.87,1.60)\end{array}$

Level of education

$\begin{array}{ll}\text { Medium } & 0.88(0.64,1.20) \\ \text { High } & 0.96(0.73,1.31)\end{array}$

Difference by age groups

The youngest participants
1.00

$1.26(0.81,1.94)$

$1.32(0.84,2.08)$

$1.50(0.97,2.34)$

$2.14(1.16,3.94)^{*}$

$1.80(1.01,3.19)^{*}$

$1.67(1.20,2.30)^{*}$

$1.29(0.94,1.77)$

$1.01(0.73,1.41)$

$1.19(0.86,1.65)$

1.00
Table 3 The association between obesity and SES among enrolled adult participants aged 18-80 years by gender and age groups in rural Hanzhong, Shaanxi province in $2010^{\mathrm{ab}}$ (Continued)

\begin{tabular}{lll}
\hline $\begin{array}{l}\text { The medium } \\
\text { participants }\end{array}$ & $1.58(1.31,1.90)^{*}$ & $1.40(1.16,1.69)^{*}$ \\
$\begin{array}{l}\text { The oldest } \\
\text { participants }\end{array}$ & $1.58(1.32,1.90)^{*}$ & $1.22(1.01,1.47)^{*}$
\end{tabular}

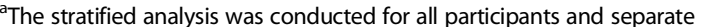
multivariate logistic models were fit for each gender groups and age groups when socio-demographic factors and risk factors were adjusted for. The low-SES group was treated as the reference group.

${ }^{b}$ Values were given as adjusted odds ratio $(95 \% \mathrm{Cl})$ unless otherwise stated. *Denote $\mathrm{P}<0.05$.

to be overweight/obese (BMI $\geq 24 \mathrm{~kg} / \mathrm{m}^{2}$, age-standardized rate 36.4\%) [17]. A study performed in Shanghai during 2007-2008 reported the prevalence of overweight/obesity $\left(B M I \geq 24 \mathrm{~kg} / \mathrm{m}^{2}\right)$ to be $43.4 \%$ [18]. A 2002 China Health and Nutrition survey indicated that $37.9 \%$ of adults aged $\geq$ 18 years were overweight/obese $\left(\mathrm{BMI} \geq 24 \mathrm{~kg} / \mathrm{m}^{2}\right)$ nationwide [19]. Globally, it was estimated that the prevalence of obesity (BMI $\geq 30 \mathrm{~kg} / \mathrm{m}^{2}$ ) was the lowest in south Asia in both men (1.4\%) and women (2.9\%) [20]. By comparison, it seems that the prevalence of overweight/obesity observed in our study population is approaching the Chinese mean level as well as the values reported in eastern China, which are also much higher than that reported in south Asia.

Our study further showed that the age-standardized prevalence of abdominal obesity had reached $33.5 \%$ for men and $37.5 \%$ for women, respectively. These results were consistent with other reported studies in China $[17,18]$. Data available from the Chinese Center for Disease Control and Prevention (CDC) estimated that the average prevalence of abdominal obesity was about $30.4 \%$ nationwide in 2004 [21]. In a 2007-2008 survey in Shanghai, there was a report of $22.4 \%$ of abdominal obesity among the participants (WC $\geq 90 \mathrm{~cm}$ for men with $27.3 \%$ and $W C \geq 85 \mathrm{~cm}$ for women with $17.1 \%$ ) [18]. Data from the Zhengjiang Province indicated that age-and-sex adjusted abdominal overweight and obesity rates were $32.2 \%$ and $12.3 \%$, respectively [17]. It is apparent from these findings that the abdominal obesity epidemic is more severe relative to the national average level, and lower than that of eastern China.

In exhaustive reviews by Sobal and Mclaren, it was concluded that the relationship between SES and obesity had two patterns: the "developing country pattern" and "developed country pattern". As one moved from high- to medium- to low-income countries, the proportion of positive SES-obesity associations increased and the proportion of negative associations decreased, for both men and women $[22,23]$. When adjusting for socio-demographic factors and possible risk factors, we found there were significant disparities in SES-obesity association between genders when measured by different SES indicators. In 
Table 4 Adjusted odds ratio (AOR) and $95 \% \mathrm{Cl}$ of risk factors for obesity across socioeconomic status (SES) by gender and age groups among enrolled adult participants of ages 18 to 80 years in rural Hanzhong, Shaanxi province in $2010^{\text {ab }}$

\begin{tabular}{|c|c|c|c|c|c|}
\hline Class differences & Farming frequency & TV viewing & Alcohol consumption & Smoking frequency & $\begin{array}{l}\text { Vegetable and } \mathrm{f} \\
\text { consumption }\end{array}$ \\
\hline \multicolumn{6}{|l|}{ Female } \\
\hline \multicolumn{6}{|c|}{ Annual net income per capita } \\
\hline Medium & $0.93(0.71,1.21)$ & $1.27(0.99,1.65)^{*}$ & $1.89(0.76,4.69)$ & $0.74(0.18,3.11)$ & $1.52(1.12,2.06)^{*}$ \\
\hline High & $0.60(0.46,0.77)^{*}$ & $1.30(1.01,1.67)$ & $1.40(0.54,3.59)$ & $1.02(0.26,3.93)$ & $2.18(1.63,2.93)^{*}$ \\
\hline \multicolumn{6}{|l|}{ Level of education } \\
\hline Medium & $1.08(0.82,1.43)$ & $1.13(0.86,1.47)$ & $1.01(0.41,2.47)$ & $0.15(0.02,1.29)$ & $1.12(0.81,1.56)^{*}$ \\
\hline High & $0.59(0.46,0.76)^{*}$ & $1.88(1.48,2.40)^{*}$ & $0.76(0.33,1.75)$ & $0.48(0.15,1.56)$ & $1.47(1.11,1.95)^{*}$ \\
\hline \multicolumn{6}{|l|}{ Male } \\
\hline \multicolumn{6}{|c|}{ Annual net income per capita } \\
\hline Medium & $1.13(0.80,1.60)$ & $1.47(1.03,2.09)^{*}$ & $1.14(0.73,1.79)$ & $1.21(0.87,1.70)$ & $1.29(0.86,1.93)$ \\
\hline High & $0.60(0.44,0.82)^{*}$ & $1.37(0.99,1.90)$ & $1.49(0.99,2.24)$ & $1.25(0.91,1.71)$ & $2.27(1.58,3.25)^{*}$ \\
\hline \multicolumn{6}{|l|}{ Level of education } \\
\hline Medium & $1.07(0.68,1.67)$ & $1.10(0.71,1.69)$ & $1.56(0.90,2.72)$ & $1.22(0.79,1.86)$ & $1.30(0.76,2.22)$ \\
\hline High & $0.53(0.36,0.77)^{*}$ & $1.73(1.20,2.51)^{*}$ & $1.42(0.87,2.31)$ & $1.12(0.78,1.61)$ & $2.16(1.38,3.38)^{*}$ \\
\hline \multicolumn{6}{|l|}{ Gender differences } \\
\hline Men & 1.00 & 1.00 & 1.00 & 1.00 & 1.00 \\
\hline Women & $1.22(1.03,1.44)^{*}$ & $0.71(0.60,0.85)^{*}$ & $0.10(0.07,0.14)^{*}$ & $0.003(0.002,0.006)^{*}$ & $1.19(0.99,1.42)$ \\
\hline
\end{tabular}

The youngest participants

Annual net income per capita

Medium

High

Level of education

Medium

High

The oldest participants

Annual net income per capita

Medium

High

$1.16(0.84,1.60)$

$0.94(0.69,1.27)$

$1.51(1.10,2.09)^{*} \quad 2.20(1.13,4.27)^{*}$

$1.37(1.00,1.87)^{*} \quad 1.39(0.69,2.80)$

$1.67(1.03,2.70)^{*}$

$1.42(0.90,2.24)$

$1.69(1.12,2.56)^{*}$

$2.23(1.52,3.27)^{*}$

Level of education

Medium

$1.13(0.82,1.57)$

$1.12(0.82,1.53)$

$0.82(0.40,1.72)$

$0.70(0.43,1.15)$

$1.51(1.00,2.29)$

High

$0.57(0.41,0.79)^{*}$

$1.77(1.27,2.46)^{*} \quad 1.05(0.54,2.03)$

$0.65(0.41,1.03)$

$2.44(1.64,3.64)^{*}$

Difference by age groups

The youngest participants

The medium participants

1.00

$1.91(1.58,2.31)^{*}$

$1.00 \quad 1.00$

$0.74(0.61,0.90)^{*}$

$0.88(0.64,1.20)$

1.00

1.00

The oldest participants

$1.27(1.07,1.52)^{*}$

$0.39(0.32,0.47)^{*} \quad 0.55(0.39,0.78)^{*}$

$1.09(0.89,1.35)$

$0.78(0.65,0.95)^{*}$

$0.94(0.76,1.17)$

$0.43(0.35,0.53)^{*}$

${ }^{a}$ The stratified analysis was conducted for all participants and separate logistic models were fit for each gender groups and age groups when socio-demographic factors were adjusted for. The low-SES group was treated as the reference group.

${ }^{b}$ Values were given as adjusted odds ratio $(95 \% \mathrm{Cl})$ unless otherwise stated.

*Denote $\mathrm{P}<0.05$.

men, the prevalence of overweight/obesity and abdominal obesity was higher in the higher income and education level groups. In women, overweight/obesity was less likely to occur in the higher education level groups when compared to low education groups, suggesting that the social patterning of weight-related attributes of women was perhaps in transition across the developmental spectrum. In addition, a higher likelihood of overweight/obesity in 
men was found relative to women as determined by our study. Such atypical SES-obesity relationships in our study were found to be similar to other studies in developing countries such as Thailand and the Philippines [24,25], indicating that the transition of SES-obesity association in women was comparatively faster than that in men. Monteiro et al. also found a similar transition, highlighting a shift of obesity towards persons with low SES as a country's annual gross national product increases [26].

Studies had shown that there might be SES differences in dietary intake, participation in physical exertion both at work and during leisure time, exposure to early life under-nutrition or over-nutrition, exposure to social or psychological stress, and exposure to health education and health-care [26-28]. These factors might further differ between the sexes, for example, adult women often have less secure and well-paid employment than men, and are both more at risk of poverty, potentially giving them less control over access to nutritious food [1]. However, gender differences associated between SES and obesity are complex and may be confounded by other factors such as health behaviors and socio-cultural norms $[29,30]$. Previous research concluded that "habitus theory" plays a vital role in gender-related differences [31]. Generally speaking, in women, a thinner body is socially valued and such opinion may be dictated by social pressures on highly educated women to be thin than highly educated men [32]. For men, a larger body size is likely to be valued as a sign of physical dominance and prowess [33]. With men being the traditional wage earners in families, it is plausible that income and pursuit of physical dominance remain linked. Thus it is not surprising to find a faster transition for SES-obesity relationship in women than men.

To further explore gender disparities in the SESobesity relationship, we analyzed the correlation between SES and specific lifestyles associated with obesity by gender among the participants after adjusting for sociodemographic factors. Overall, duration of TV viewing was positively associated with SES based on education level and income in both genders. Nevertheless, farming frequency decreased with the SES of participants. In our study, it was also observed that women had less duration of TV viewing and alcohol consumption, but they did take on much more farming work than men. In order to bring in more money and supplement farming income, most men leave the village to work temporary jobs in urban areas, while more women stay at home and occupy themselves with farming. Due to the low economic level in the surveyed areas, television viewing was considered as the primary leisure after work among local participants, especially in the high-SES groups. Thus, lifestyle differences by gender may contribute to the sex disparity observed in the SES-obesity relationship.
In the present analyses, the age effect was strong for both sexes: obesity rose with age. It should be noted that duration of TV viewing, alcohol consumption as well as vegetable and fruit consumption were lower in the oldest participants compared to the youngest participants, while farming frequency was just the opposite. However, after the inclusion of multiple lifestyle factors, we still noted a strong positive association between age and obesity in this population, which indicated the lifestyle factors have limited effect on age-obesity association. This is in line with a previous study performed in Thailand [25].

Several limitations of this study should be noted. First, due to the cross-sectional design of our study, we cannot draw any cause-effect conclusion based on the study results. Second, as the study is confined to rural Northwest China, the conclusions from this study may not be generalizable to other areas in China. Third, anthropometric indicators such as height, weight, and WC were measured directly but information on lifestyles were selfreported. Thus, the possibility of information bias should be considered. Despite these limitations, this is the first study to determine the relationship between SES and obesity in rural Northwest China, which provides important clues for prevention and control of local obesity.

\section{Conclusions}

In summary, there is an obesity epidemic in rural Northwest China, which is increasingly approaching the national average level. On the whole, the prevalence of obesity were higher in men than in women, and positively associated with age. The gender difference in SES-obesity association was clearly observed, suggesting that the transition of SES-obesity association from "developing country pattern" into "developed country pattern" in women was comparatively faster than that in men. After adjusting for multiple lifestyle factors, we still discerned a strong positive age-obesity association in the population. Therefore, it is necessary and crucial to implement interventional-based strategies focused on gender and age to reduce the obesity epidemic in rural Northwest China.

\section{Competing interests}

The authors declare that they have no competing interest.

\section{Authors' contributions}

LP and YC designed the prescription study, conducted the data analysis and prepared the manuscript; SY and YK collected the data; HY contributed to the design and analysis of the study and the preparation of the manuscript. All authors read and approved the final manuscript.

\section{Acknowledgments}

This work was supported by the National Natural Science Foundation of China (Grant No.81230016) and the China Medical Board (Grant No. 08-925). We would like to thank all participants and investigators in this study. 


\section{Author details}

1 Department of Epidemiology and Health Statistics, School of Public Health, Xi'an Jiaotong University Health Science Center, No. 76 West Yanta Road, PO Box 46, Xi'an, Shaanxi 710061, PR China. ${ }^{2}$ Department of Nutrition and Food Safety Research, School of Public Health, Xi'an Jiaotong University Health Science Center, Xi'an, Shaanxi 710061, PR China.

Received: 21 May 2014 Accepted: 3 February 2015

Published online: 19 February 2015

\section{References}

1. Wells JC, Marphatia AA, Cole TJ, McCoy D. Associations of economic and gender inequality with global obesity prevalence: Understanding the female excess. Soc Sci Med. 2012;75:482-90

2. WHO. Obesity: preventing and managing the global epidemic Report of a WHO Consultation (WHO Technical Report Series 894). Geneva: World Health Organization; 2000.

3. James WP. What are the health risks? The medical consequences of obesity and its health risks. Exp Clin Endocrinol Diabetes. 1998:106:1-6.

4. Novak M, Ahlgren C, Hammarstrom A. A life-course approach in explaining social inequity in obesity among young adult men and women. Int J Obes (Lond). 2006:30:191-200.

5. Wu Y. Overweight and obesity in China. BMJ. 2006;19:362-3.

6. Youfa W, Qi Z. Are American children and adolescents of low socioeconomic status at increased risk of obesity? Changes in the association between overweight and family income between 1971 and 2002. Am J Clin Nutr. 2006;84:707-16.

7. Wang Y. Cross-national comparison of childhood obesity: the epidemic and the relationship between obesity and socioeconomic status. Int J Epidemiol. 2001;30:1129-36

8. Wang $Y$, Monteiro C, Popkin BM. Trends of obesity and underweight in older children and adolescents in the United States, Brazil, China, and Russia. Am J Clin Nutr. 2002;75:971-7.

9. Wang Y, Mi J, Shan XY, Wang QJ, Ge KY. Is China facing an obesity epidemic and the consequences? The trends in obesity and chronic disease in China. Int J Obes (Lond). 2007;31:177-88.

10. Razak F, Anand SS, Shannon H, Vuksan V, Davis B, Jacobs R, et al. Defining obesity cut points in a multiethnic population. Circulation. 2007;115:2111-8.

11. Ko GT, Chan JC, Chow CC, Yeung VT, Chan WB, So WY, et al. Effects of obesity on the conversion from normal glucose tolerance to diabetes in Hong Kong Chinese. Obes Res. 2004;12:889-95.

12. Jia WP, Xiang KS, Chen L, Lu JX, Bao YQ, Wu YM, et al. A comparison of the application of two working definitions of metabolic syndrome in Chinese population. Natl Med J China. 2004:84:534-8 (in chinese).

13. Zhou BF. Effect of Body Mass Index on All-cause Mortality and Incidence of Cardiovascular Diseases Report for Meta-analysis of Prospective Studies Open Optimal Cut-off Points of Body Mass Index in Chinese Adults. Biomed Environ Sci. 2002;15:245-52

14. Cooperative Meta-analysis Group of China Obesity Task Force. Predictive values of body mass index and waist circumference to risk factors of related diseases in Chinese adult population. Chin J Epidemiol. 2002;23(1):5-10 (in Chinese).

15. Melnyk BM, Jacobson D, Kelly S, Belyea M, Shaibi G, Small L, et al. Promoting healthy lifestyles in high school adolescents: a randomized controlled trial. Am J Prev Med. 2013:45(4):407-15.

16. Qin X, Zhang Y, Cai Y, He M, Sun L, Fu J, et al. Prevalence of obesity, abdominal obesity and associated factors in hypertensive adults aged 45-75 years. Clin Nutr. 2013;32(3):361-7.

17. Xiao Y, Zhao N, Wang H, Zhang J, He Q, Su D, et al. Association between socioeconomic status and obesity in a Chinese adult population. BMC Public Health. 2013:13:355

18. Hou X, Liu Y, Lu H, Ma X, Hu C, Bao Y, et al. Ten-year changes in the prevalence of overweight, obesity and abdominal obesity among the Chinese adults in urban Shanghai, 1998-2007- comparison of two cross-sectional surveys. BMC Public Health. 2013;13:1064.

19. Wang LD. Nutrition and health survey of Chinese residents. Beijing: People's Medical Publishing House; 2002 (in Chinese).

20. Finucane MM, Stevens GA, Cowan MJ, Danaei G, Lin JK, Paciorek CJ, et al. National, regional, and global trends in body-mass index since 1980: systematic analysis of health examination surveys and epidemiological studies with 960 country-years and 9.1 million participants. Lancet. 2011;377:557-67.
21. The Center of Chronic Non-Communicable Disease of Chinese Center for Disease Control and Prevention. The surveillance reports of chronic disease and related risk factors in China (2004). Beijing: Peking Union Medical College Press; 2009. in Chinese.

22. Sobal J, Stunkard AJ. Socioeconomic status and obesity: a review of the literature. Psychol Bull. 1989:105:260-75.

23. Mclaren L. Socioeconomic status and obesity. Epidemiol Rev. 2007;29:29-48.

24. Dahly DL, Gorden-larson P, Popkin BM, Kaufman JS, Adair LS. Associations between multiple indicators of socioeconomic status and obesity in young adult Filipinos vary by gender, urbanicity, and indicator used. J Nutr. 2010;140:366-70.

25. Seubsman SA, Lim LL, Banwell C, Sripaiboonkit C, Kelly M, Bain C, et al. Socioeconomic status, sex, and obesity in a large national cohort of 15-87 year old open university students in Thailand. J Epidemiol. 2010;20:13-20.

26. Monteiro CA, Moura EC, Conde WL, Popkin BM. Socioeconomic status and obesity in adult populations of developing countries: a review. Bull World Health Organ. 2004:82(12):940-6.

27. Dorling D, Mitchell R, Pearce J. The global impact of income inequality on health by age: an observational study. BMJ. 2007;335(7625):873.

28. Marmot MG. The status syndrome: How social standing affects our health and longevity. London: Bloomsbury; 2004

29. Kavikondala S, Schooling CM, Jiang CQ, Zhang WS, Cheng KK, Lam TH, et al. Pathways to obesity in developing population: The Guangzhou Biobank Cohort Study. Int J Epidemiol. 2009;8:72-82.

30. Seppänen-Nuijten $E$, Lahti-Koski M, Männistö S, Knekt P, Rissanen H, Aromaa $A$, et al. Fat free mass and obesity in relation to educational level. BMC Public Health. 2009;9:448.

31. Bourdieu P. Distinction: A Social Critique of the Judgment of Taste. London: Routledge and Kegan Paul Ltd; 1984.

32. Yoon YS, Oh SW, Park HS. Socioeconomic status in relation to obesity and abdominal obesity in Korean adults: a focus on sex differences. Obesity (Silver Spring). 2006;14:909-19.

33. McVey G, Tweed S, Blackmore E. Correlates of weight loss and muscle-gaining behavior in 10- to 14-year-old males and females. Prev Med. 2005;40:1-9.

\section{Submit your next manuscript to BioMed Central and take full advantage of:}

- Convenient online submission

- Thorough peer review

- No space constraints or color figure charges

- Immediate publication on acceptance

- Inclusion in PubMed, CAS, Scopus and Google Scholar

- Research which is freely available for redistribution 